\section{Kidney \\ Blood Pressure Research}

Kidney Blood Press Res 2018;43:1898-1907

DOI: 10.1159/000496001

Published online: 14 December 2018

Accepted: 5 December 2018

This article is licensed under the Creative Commons Attribution-NonCommercial-NoDerivatives 4.0 InternaThis article is licensed under the Creative Commons Attribution-NonCommercial-NoDerivatives 4.0 interna-
tional License (CC BY-NC-ND) (http://www.karger.com/Services/OpenAccessLicense). Usage and distribution for commercial purposes as well as any distribution of modified material requires written permission.

\title{
Bioinformatic Analyses of Renal Ischaemia- Reperfusion Injury Models: Identification of Key Genes Involved in the Development of Kidney Disease
}

\author{
Kai Zhu Ting Zheng Xinghua Chen Huiming Wang \\ Division of Nephrology, Renmin Hospital of Wuhan University, Wuhan, China
}

\section{Key Words}

Renal ischemia-reperfusion injury - Differentially expressed genes - Kyoto Encyclopedia of Genes and Genomes pathway - Reactome pathway - Protein-protein interaction - miRNAtarget gene network

\begin{abstract}
Background/Aims: To develop a novel strategy for the treatment of kidney disease, we explored potential molecular targets involved in the development of renal ischaemiareperfusion injury (IRI). Methods: The Gene expression profile data of GSE27274, including controls and rats subjected to renal IRI and reperfusion for $24 \mathrm{~h}$ (IR24) or $120 \mathrm{~h}$ (IR120), was obtained from the Gene Expression Omnibus database. Differentially expressed genes (DEGs) were analysed using the limma package. Gene Ontology (GO) and pathway functional enrichment analyses of common DEGs were carried out. Protein-protein interactions (PPI) and miRNA-DEG network analyses were performed using the STRING database and WebGestalt, respectively, followed by network construction using Cytoscape. Results: In total, 80 common DEGs (41 up- and 39 downregulated genes) between IR24 and IR120 were screened. Genes encoding tissue inhibitor of matrix metalloproteinase-1 (Timp1), secreted phosphoprotein 1 (Spp1) and dimethylglycine dehydrogenase (Dmgdh) were identified as hub genes in the PPI network and may be significant in the development of renal IRI. Upregulated Spp 1 was enriched in the inflammatory response, and downregulated Dmgdh was enriched in the catabolic process of the amino acid betaine. In reactome pathway analyses, Spp 1 was enriched in tolllike receptor signalling, and Dmgdh was enriched in glycine, serine and threonine metabolic pathways. The common DEGs were mainly regulated by 15 miRNA clusters. Conclusion: Timp1, Spp1, Dmgdh, miR-142-5p and miR-181a may be potential targets or biomarkers for the development of renal IRI.




\section{Kidney Blood Pressure Research}

Zhu et al.: Bioinformatic Analyses of Renal Ischemia-Reperfusion Injury Models

\section{Introduction}

Acute kidney injury (AKI) is associated with high healthcare costs, morbidity and mortality in the clinic and has become an important public health concern worldwide [1]. Recently, AKI has been suggested to lead to long-term outcomes, including the development and progression of chronic kidney disease (CKD) and end-stage renal disease (ESRD), even in those patients who recover [2,3]. Although the needed to eliminate the short- and longterm outcomes of AKI is urgent, no effective therapy exists to prevent the development of these renal diseases.

Renal ischaemia-reperfusion injury (IRI) is one of the major causes of AKI in hospital settings [4]. The complicated cellular pathophysiology in IRI development, including cell adhesion, proliferation and cytokine secretion, is associated with inflammation, the innate immune response, and injury to tubular, endothelial and vascular components [5, 6]. Many factors are thought to relate to the development of renal IRI. Yu TM et al. [7] demonstrated that RANTES (regulated on activation, normal T-cell expressed and secreted), produced by renal tubular cells, is a major chemokine in the development of renal IRI. Furthermore, an inhibitor of the complement $\mathrm{C} 1$ fraction (C1INH) prevented inflammatory reactions, neutrophil migration and the development of fibrosis in a murine model of renal IRI [8]. In addition, microRNAs (miRNAs), non-coding RNAs that regulate their target mRNAs via a post-transcriptional repression process, have a potential effect in renal IRI development [9]. miR-21 is upregulated to protect against apoptosis of tubular epithelial cells during the development of renal IRI [10]. On the other hand, increased miR-24 promotes apoptosis of endothelial and tubular epithelial cells [11]. While multiple signalling pathways have been reported, the molecular mechanisms underlying the development of renal IRI are still unclear.

In the present study, the differentially expressed genes (DEGs) were screened from the GSE27274 dataset between sham controls and two groups of rats subjected to different time-points of reperfusion injury. By performing functional enrichment, protein-protein interaction (PPI) and miRNA-target gene network analyses, several candidate genes were demonstrated to be potential targets or biomarkers for diagnosing or treating the development of renal IRI.

\section{Materials and Methods}

\section{Affymetrix microarray data acquisition}

Gene expression profile data from GSE27274 were obtained from the NCBI Gene Expression Omnibus (GEO, http://www.ncbi.nlm.nih.gov/geo/) database. The dataset was based on the GPL6101 Illumina platform ratRef-12 v1.0 expression beadchip and deposited by Krishnamoorthy A et al. [12]. Included in the dataset were 24 samples from bilateral ischaemia-reperfusion (IR) kidney injury and its sham controls. Renal cortex and medulla samples obtained at $24 \mathrm{~h}$ or $120 \mathrm{~h}$ of reperfusion were used for further analysis. To clarify the genes and pathways in the whole kidney, cortex and medulla samples from the corresponding rats were pooled.

\section{Data preprocessing and DEG analysis}

The raw array data were normalized by the Robust Multiarray Average (RMA) method [13]. The mean value of multiple probes for a single gene was calculated. The linear models for microarray data (limma) package [14] in R were used to analyse the DEGs from renal IRI compared with those from sham controls, and the $\mid \log$ Fold Change (FC) $\mid>1.5$ and p-values $<0.05$ were considered the threshold as previously described [15]. 


\section{Kidney Blood Pressure Research}

Gene ontology (GO) and pathway functional enrichment analyses

The online functional annotation tool DAVID (Database for Annotation, Visualization and Integrated Discovery) was used to understand the biological meaning of genes [16]. The up- and downregulated DEGs in renal IRI were used to perform GO biological process (BP), cellular components (CC), molecular function (MF) and Kyoto Encyclopedia of Genes and Genomes (KEGG) pathway enrichment analyses using the DAVID functional classification tool. The cut-off values for the GO analysis were set at $\mathrm{p}<0.05$ and enrichment score more than 2 and for the KEGG Pathway analysis at $\mathrm{p}<0.05$.

\section{PPI network analysis}

The Search Tool for the Retrieval of Interacting Genes (STRING) [17] database is a global resource for predicting PPIs. In the present study, DEGs were uploaded to the STRING online tool, and combined scores $>0.4$ were selected as significant interactions. PPI networks were visualized by Cytoscape ${ }^{\circledR}$ version 3.4.0 software [18].

\section{Interaction network analysis between DEGs and miRNAs}

The WEB-based Gene Set Analysis Toolkit (WebGestalt) [19] is an online integrated data mining system. The regulatory miRNAs of both up- and downregulated DEGs were predicted by using WebGestalt, and the thresholds were set at $p$ value $<0.05$ and enriched genes $>2$. Up- and downregulated DEGs and the miRNA network were visualized with Cytoscape.

\section{Results}

\section{Identification of DEGs}

The DEGs between sham controls and the samples obtained at $24 \mathrm{~h}$ (IR24) or $120 \mathrm{~h}$ (IR120) of reperfusion after renal ischaemia are shown in Fig. 1. Compared with the expression profiles from sham controls, a total of 504 DEGs (182 up- and 322 downregulated genes) were found in IR24 rats. Moreover, 111 DEGs (66 up- and 45 downregulated genes) were screened in IR120 rats. In total, 80 DEGs were common to both the IR2 4 and IR120 samples, with 41 upregulated and 39 downregulated genes (Fig. 2).

\section{Functional enrichment analyses of common DEGs}

To identify the functional enrichment in the development of renal IRI, GO enrichment analyses were performed for up- and downregulated common DEGs (Table 1). Upregulated common DEGs were significantly enriched in 27 GO terms for BP. The BP terms with the smallest $\mathrm{P}$ value in the two different reperfusion groups included inflammatory response, cell adhesion, innate immune response and cell proliferation. Downregulated common DEGs were enriched in amino-acid betaine catabolic processes, transmembrane transport, homocysteine and one-carbon metabolic processes.

Furthermore, significantly enriched pathways of up- and downregulated common DEGs were obtained by utilizing DAVID. As shown in Table 2, the main enriched KEGG pathways of upregulated DEGs were toll-like receptor signalling, complement and coagulation cascades and ECM-receptor interaction. Downregulated DEGs were enriched in glycine, serine, threonine, cysteine and methionine metabolic pathways.

\section{PPI network}

Based on the STRING database web tool, PPI networks of the 80 common DEGs were constructed with a combined score of $>0.4$. As shown in Fig. 3 , the PPI had 36 nodes and 54 edges. Genes with the highest interaction degrees encoded tissue inhibitor of matrix metalloproteinase-1 (Timp1; degree $=10)$, angiotensinogen (Agt; degree=8), dimethylglycine dehydrogenase (Dmgdh; degree=7) and secreted phosphoprotein 1 (also known as osteopontin; Spp1; degree=7). 


\section{Kidney Blood Pressure Research}

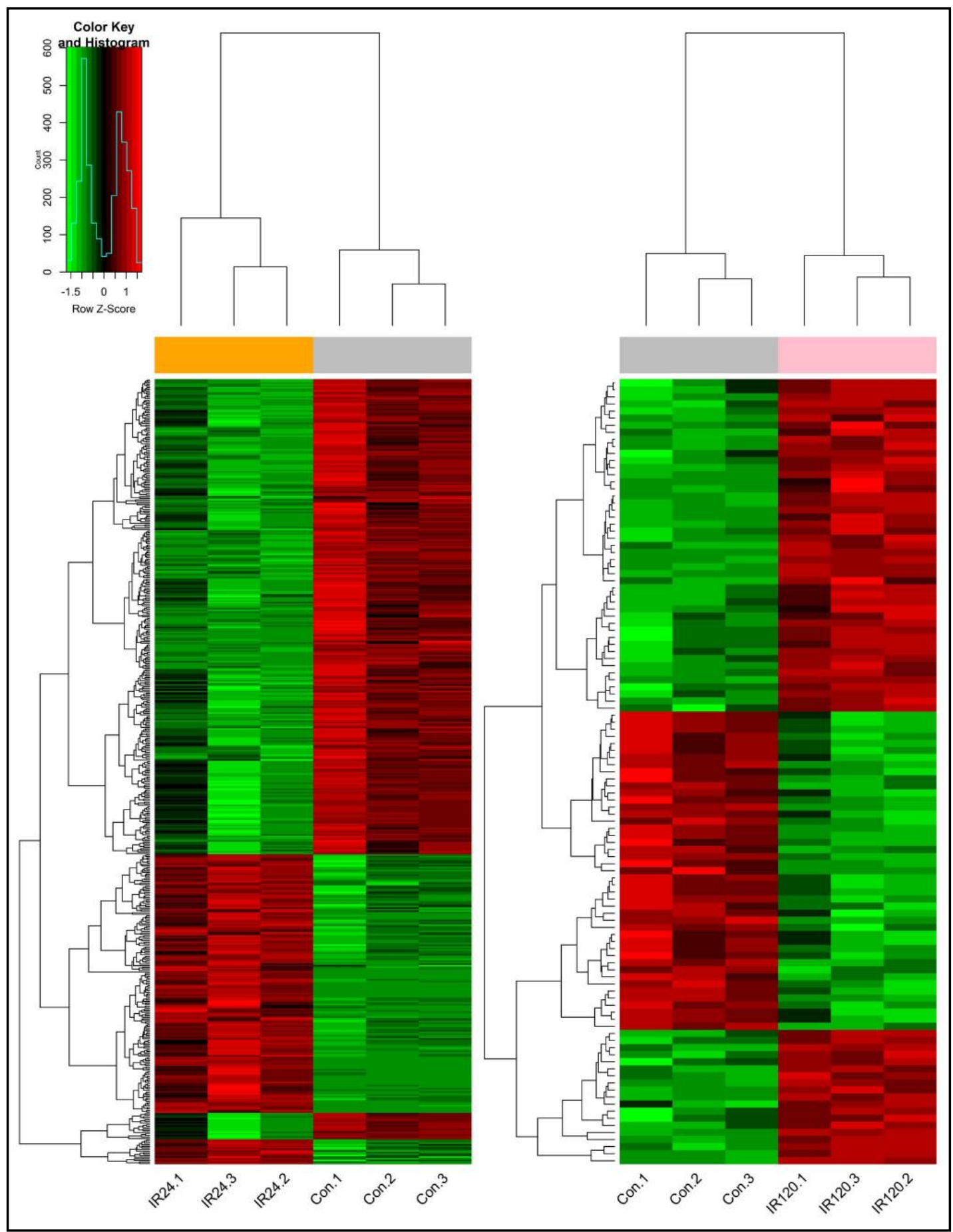

Fig. 1. The heat maps of the top 50 DEGs. The left panel represents DEGs of rats subjected to renal IRI and reperfusion for $24 \mathrm{~h}$, the right represents reperfusion for $120 \mathrm{~h}$. Each row represents a gene, and each column represents a sham control or a rat underwent renal IRI. Each colored square shows the relative change of a single gene in a single rat, red color indicates higher and green color indicates lower expression levels. Black color represents no change in expression. 


\section{Kidney Blood Pressure Research}

Fig. 2. Common DEGs in rats underwent renal IRI at two time-points of reperfusion. $24 \mathrm{~h}$ and $120 \mathrm{~h}$ indicate $20 \mathrm{~min}$ of ischemia followed by $24 \mathrm{~h}$ and $120 \mathrm{~h}$ of reperfusion, respectively. Venn diagram has shown 80 common DEGs at two groups of rats subjected to different time-points of reperfusion injury. The red and green arrows represent up- and downregulated genes, respectively.

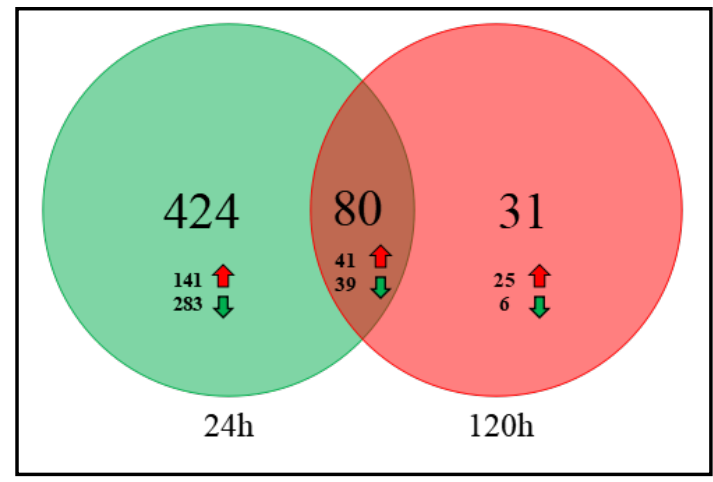

Table 1. The GO terms of the 80 common DEGs with P-Values < 0.05 . BP: biological process; CC: cellular component; MF: molecular function; GO: gene ontology; Count: the DEGs number enriched in the corresponding GO term

\begin{tabular}{|c|c|c|c|}
\hline GO ID & Term & Count & P-Value \\
\hline \multicolumn{4}{|c|}{ Up-regulated genes } \\
\hline \multicolumn{4}{|c|}{ GO-BP terms } \\
\hline GO:0071347 & cellular response to interleukin-1 & 5 & $2.25 \mathrm{E}-05$ \\
\hline GO:0006954 & inflammatory response & 6 & $1.36 \mathrm{E}-04$ \\
\hline GO:0071222 & cellular response to lipopolysaccharide & 5 & $1.79 \mathrm{E}-04$ \\
\hline GO:0009615 & response to virus & 4 & $3.65 \mathrm{E}-04$ \\
\hline GO:0006898 & receptor-mediated endocytosis & 4 & $6.16 \mathrm{E}-04$ \\
\hline GO:0007155 & cell adhesion & 5 & $9.69 \mathrm{E}-04$ \\
\hline GO:0045087 & innate immune response & 5 & $9.69 \mathrm{E}-04$ \\
\hline GO:0071354 & cellular response to interleukin-6 & 3 & $1.04 \mathrm{E}-03$ \\
\hline GO:0032496 & response to lipopolysaccharide & 5 & $1.26 \mathrm{E}-03$ \\
\hline GO:0008284 & $\begin{array}{l}\text { positive regulation of cell proliferation } \\
\text { GO-CC terms }\end{array}$ & 6 & $1.50 \mathrm{E}-03$ \\
\hline GO:0005615 & extracellular space & 19 & $1.62 \mathrm{E}-13$ \\
\hline GO:0070062 & extracellular exosome & 18 & $1.46 \mathrm{E}-07$ \\
\hline GO:0009986 & cell surface & 10 & 4.66E-07 \\
\hline GO:0072562 & blood microparticle & 6 & $1.44 \mathrm{E}-06$ \\
\hline GO:0005604 & basement membrane & 5 & $1.69 \mathrm{E}-05$ \\
\hline GO:0031012 & extracellular matrix & 6 & $5.92 \mathrm{E}-05$ \\
\hline GO:0031982 & vesicle & 5 & $1.44 \mathrm{E}-04$ \\
\hline GO:0005578 & proteinaceous extracellular matrix & 5 & $8.01 \mathrm{E}-04$ \\
\hline GO:0009897 & external side of plasma membrane & 5 & $9.78 \mathrm{E}-04$ \\
\hline \multicolumn{3}{|c|}{ GO-MF terms } & $1.04 \mathrm{E}-03$ \\
\hline GO:0008201 & heparin binding & 5 & $7.30 \mathrm{E}-05$ \\
\hline GO:0005125 & cytokine activity & 5 & $9.68 \mathrm{E}-05$ \\
\hline GO:0002020 & protease binding & 4 & $8.82 \mathrm{E}-04$ \\
\hline GO:0048248 & CXCR3 chemokine receptor binding & 2 & $7.78 \mathrm{E}-03$ \\
\hline \multicolumn{4}{|c|}{ Down-regulated genes } \\
\hline GO-BP terms & & & \\
\hline GO:0006579 & amino-acid betaine catabolic process & 2 & $2.74 \mathrm{E}-03$ \\
\hline GO:0009725 & response to hormone & 3 & 8.03E-03 \\
\hline GO:0050667 & homocysteine metabolic process & 2 & $1.23 \mathrm{E}-02$ \\
\hline GO:0060351 & cartilage development involved in endochondral bone morphogenesis & 2 & $1.36 \mathrm{E}-02$ \\
\hline GO:0051593 & response to folic acid & 2 & $2.57 \mathrm{E}-02$ \\
\hline GO:0055085 & transmembrane transport & 3 & $3.61 \mathrm{E}-02$ \\
\hline GO:0006730 & $\begin{array}{l}\text { one-carbon metabolic process } \\
\text { GO-CC terms }\end{array}$ & 2 & $3.77 \mathrm{E}-02$ \\
\hline GO:0070062 & $\begin{array}{c}\text { extracellular exosome } \\
\text { GO-MF terms }\end{array}$ & 10 & $5.74 \mathrm{E}-03$ \\
\hline GO:0072341 & modified amino acid binding & 2 & $1.00 \mathrm{E}-02$ \\
\hline
\end{tabular}

\section{Potential regulatory miRNAs associated with DEGs}

In AKI and CKD, microRNAs (miRNAs) are one of the most common epigenetic factors regulating gene expression $[10,20]$. The online tool WebGestalt was used to retrieve potential regulatory miRNAs associated with DEGs, and the miRNA-DEG network was visualized with Cytoscape. As shown in Fig. 4A, the network of miRNAs and upregulated DEGs contained 17 nodes and 19 edges. Adamts1, Hspa2, Fn1 and Abcg1 had the highest degrees of 5, 3, 3 and 


\section{Kidney Blood Pressure Research}

Table 2. The Reactome pathway enrichment analyses of the 80 common DEGs (P-Values < 0.05)

\begin{tabular}{|c|c|c|c|c|}
\hline Category & Term & Count & Genes & P Value \\
\hline \multicolumn{5}{|c|}{ Up-regulated DEGs } \\
\hline rno04620 & Tolllike receptor signaling pathway & 4 & CXCL11, CD14, SPP1, CXCL10 & $1.34 \mathrm{E}-03$ \\
\hline rno05150 & Staphylococcus aureus infection & 3 & ICAM1, C1QB, CFI & $6.74 \mathrm{E}-03$ \\
\hline rno04610 & Complement and coagulation cascades & 3 & C1QB, FGB, CFI & $1.17 \mathrm{E}-02$ \\
\hline rno04512 & ECM-receptor interaction & 3 & LAMC2, SPP1, FN1 & $1.76 \mathrm{E}-02$ \\
\hline rno05146 & Amoebiasis & 3 & LAMC2, CD14, FN1 & $2.70 \mathrm{E}-02$ \\
\hline \multicolumn{5}{|c|}{ Down-regulated DEGs } \\
\hline rno01100 & Metabolic pathways & 11 & MUT, MAT2A, CSAD, UPB1, BHMT, DMGDH, CYP2E1, CHPT1, & $1.87 \mathrm{E}-04$ \\
\hline rno00260 & Glycine, serine and threonine metabolism & 3 & BHMT, DMGDH, CBS & $3.56 \mathrm{E}-03$ \\
\hline rno00270 & Cysteine and methionine metabolism & 3 & MAT2A, BHMT, CBS & $3.74 \mathrm{E}-03$ \\
\hline
\end{tabular}

Fig. 3. The PPI networks of DEGs. The red and green nodes represent the up- and downregulated DEGs, respectively. The predicated and precise results are indicated by black edges.

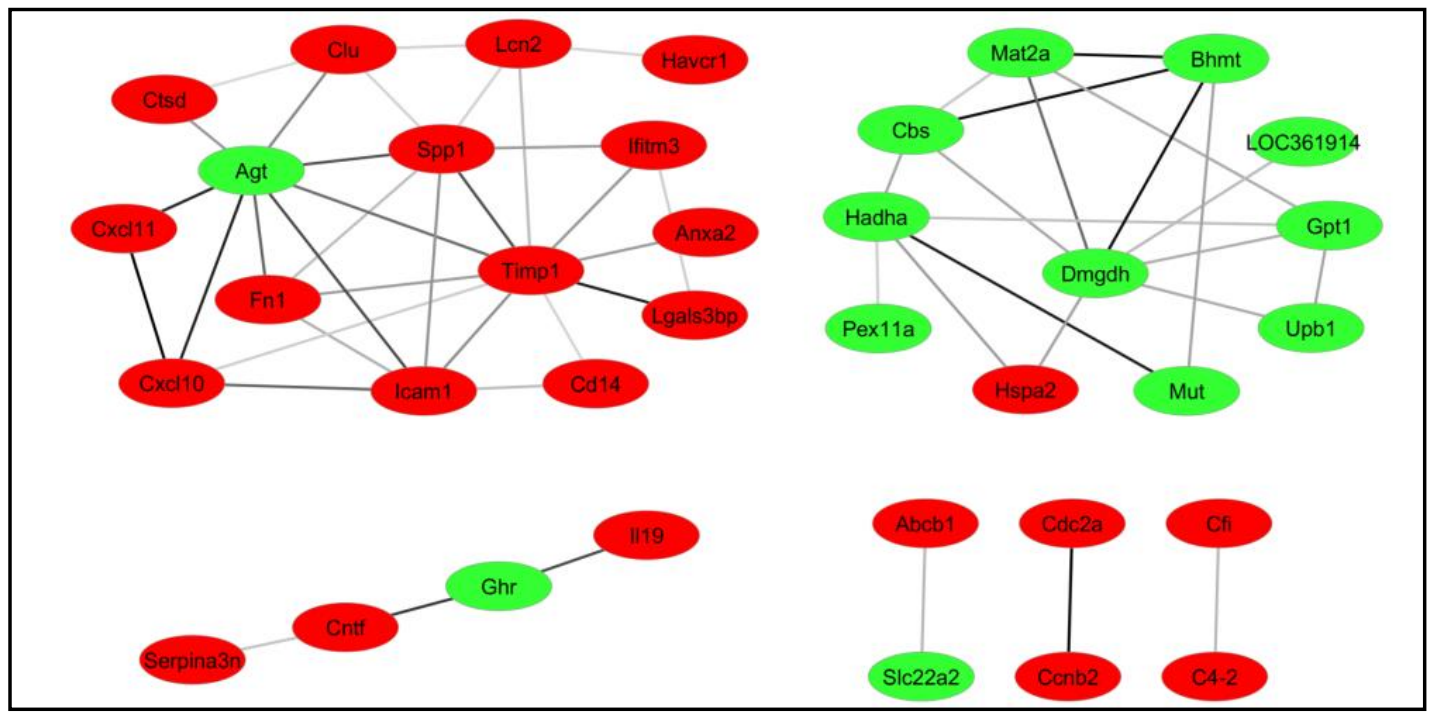

3 , respectively. miR-142-5p was demonstrated to have an important role in regulating the highest number of upregulated DEGs, including Hspa2, Abcg1, Adamts1 and Tpbg. On the other hand, the network of miRNA and downregulated DEGs contained 12 nodes and 9 edges (Fig. 4B). Mat2a and Timp3 showed the highest degrees of 3 and 2, respectively. Moreover, miR-181a, miR-181b, miR-181c and miR-181d were found to regulate 3 of the target genes, Mat2a, Timp3 and Igsf11.

\section{Discussion}

In the present study, 80 common DEGs were extracted at $24 \mathrm{~h}$ (IR24) and $120 \mathrm{~h}$ (IR120) of reperfusion after renal IRI in rats. Spp1, Timp1 and Dmgdh demonstrated higher degrees in the PPI networks and may be potential key genes in the development of renal IRI. Interestingly, the upregulated DEGs were enriched in BPs and pathways associated with inflammation. On the other hand, the downregulated DEGs were enriched in the catabolic process and metabolic pathways of the amino-acid betaine. Finally, miR-181 was suggested to have a key role in renal IRI development.

Damaged renal cells secrete proinflammatory cytokines to promote inflammation, which in turn injures renal cells in AKI [1]. Inflammation has therefore been considered one of the most important mechanisms contributing to the pathophysiology of AKI, including renal IRI [21]. In this study, the upregulated DEG Spp1 was a key gene in the PPI networks and was enriched in BP terms and pathways associated with inflammation. Spp1, also known as osteopontin, is a secreted glycoprotein that acts as a proinflammatory cytokine and is highly 


\section{Kidney Blood Pressure Research}

A

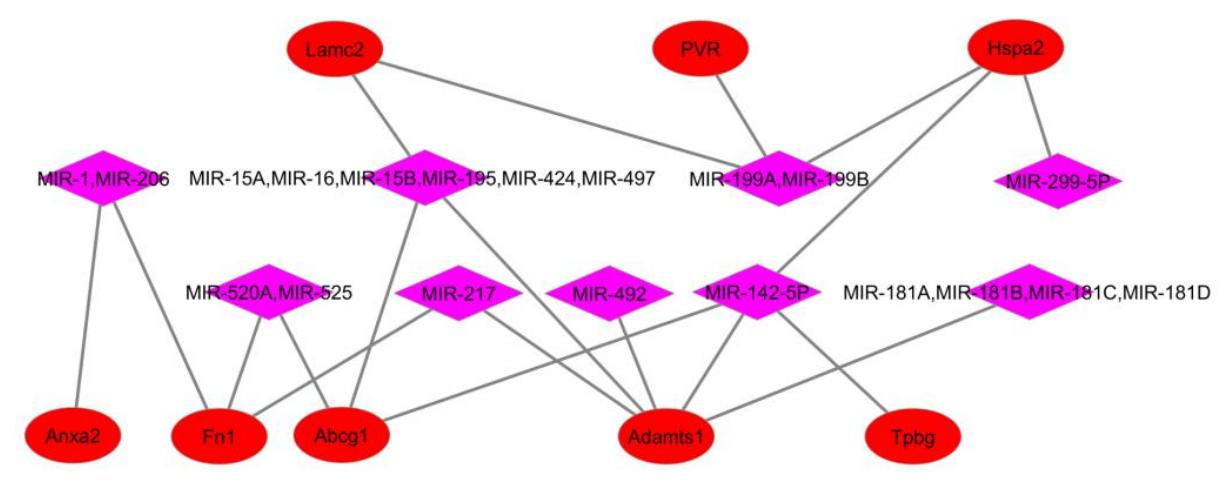

B

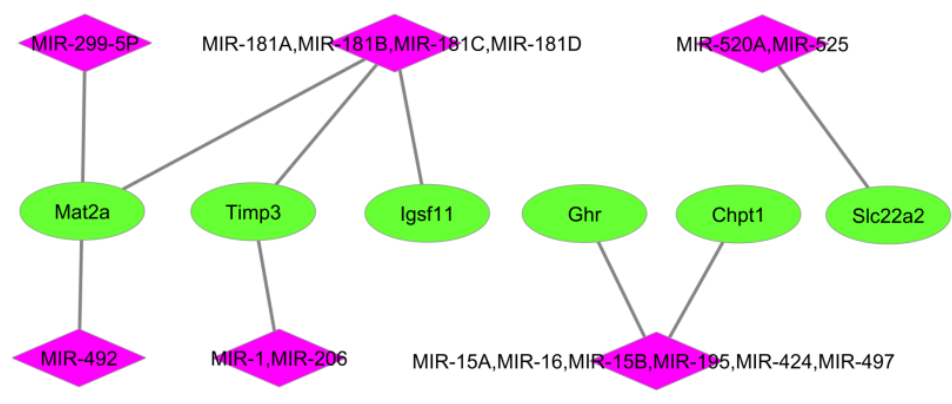

Fig. 4. Regulatory network of miRNA-common DEGs. Upregulated (A) and downregulated (B) networks are represented by miRNA (pink diamond), upregulated common DEGs (red circular nodes) and downregulated common DEGs (green circular nodes). Regulating relationships are represented by arrow edges.

expressed in the kidney [22]. Although Spp1 was demonstrated to prevent renal injury at $24 \mathrm{~h}$ after reperfusion of IRI in female mice [23], other investigators observed promotion of inflammation by Spp1 via enhanced infiltration of natural killer (NK) cells in IRI male mice $[24,25]$. Furthermore, Spp1 also led to renal inflammation in chronic aldosterone-treated mice and in ApoE-deficient mice on a high-cholesterol diet [26, 27]. Although the role of Spp1 in the early stage of IRI is controversial depending upon sexual differences, it may at least have a potential role in promoting renal inflammation in males during IRI development.

Timp1 is the other hub gene identified by the PPI network analysis of upregulated DEGs. The protein encoded by Timp1 is a member of tissue inhibitors of metalloproteinases (TIMPS), which are regulators of matrix metalloproteinases (MMPs) [28]. In addition to matrix degradation, TIMP1 also participates in inflammation, apoptosis and cell growth [29]. Although Timp1 deficiency failed to ameliorate renal interstitial fibrosis in a murine model of unilateral urethral obstruction (UUO) due to compensatory increases in TIMP2, TIMP3 and PAI-1 mediating renal fibrosis [30], over-expression of TIMP1 deteriorated interstitial fibrosis by promoting the inflammatory response in the UUO model [31]. On the other hand, Timp1 was also considered a urinary biomarker in cisplatin- and sepsis-induced AKI [32, 33]. Accordingly, TIMP1 may not be a direct target for the treatment of renal fibrosis, but it may become a potential biomarker for study of the development of renal IRI.

The third hub gene identified by the PPI network analysis of downregulated DEGs is $D m g d h$, which was also enriched in BP terms related to the catabolic process and metabolic pathways of the amino-acid betaine. Dimethylglycine dehydrogenase, encoded by Dmgdh, is a mitochondrial matrix enzyme involved in the metabolism of choline to glycine [34]. Glycine was reported to possess anti-inflammatory and immunomodulatory roles against 


\section{Kidney \\ Blood Pressure Research}

ischaemia-induced renal injury [35]. In fact, glycine protected against mild unilateral IRI (15 min ischaemia) [36]. Conversely, in severe bilateral IRI (40 min ischaemia) in rats, glycine exacerbated oxidative stress and renal cell injury through binding and activating $\mathrm{N}$-methylD-aspartate (NMDA) receptors [37]. These two contrasting findings in glycine-treated rats may be attributed to sexual difference, strain background or degree of renal ischaemia. Overall, Dmgdh might at least play a role in mild IRI.

Up- and downregulated networks of miRNA-targeted DEGs were predicted and constructed. miR-142-5p in upregulated network was calculated to regulate Adamts1, Hspa2, Abcg1 and Tpbg. In the downregulated network, miR-181a, miR-181b, miR-181c and miR-181d were predicted to regulate Mat2a, Timp3 and Igsf11. Among these miRNAs, miR-142-5p was identified as a candidate biomarker of renal fibrosis [38]. miR-181a was documented to mediate cell apoptosis in cisplatin-treated HK-2 cells [39]. Furthermore, among these miRNA-targeted genes, Timp3-encoded protein has been demonstrated not only to protect against inflammation, apoptosis and tubulointerstitial fibrosis in the early stage of renal injury following UUO in mice [40] but also to inhibit breakdown enzymes of capillary basement membrane, including ADAMTS1 (a disintegrin and metalloproteinase with thrombospondin motif-1, Adamts1-encoded protein) [41]. ADAMTS1, a secreted metalloproteinase with angiogenesis inhibition, is considered as a mediator of renal vascular stability. Its expression was increased in proximal tubular cells following post-ischaemia of renal IRI and in pericytes after UUO administration [41, 42]. Therefore, miR-142-5p, miR181a and their target genes may have critical roles in the development of renal IRI.

Although Hmox1, complement/coagulation cascades and the metabolic pathway of glycerophospholipid were previously reported to be potential targets for the early stage of renal IRI [43], our findings may provide novel targets or biomarkers for further research, diagnosis and treatment of renal IRI. Certainly, animal experiments and clinical studies are needed to confirm their significance in the development of renal IRI.

\section{Conclusion}

The present study pointed out that the Spp1, Timp1, and Dmgdh genes, with their associated BP terms and pathways, have potential roles in the development of renal IRI. Furthermore, miR-142-5p and miR-181a might be key miRNAs that modulate renal IRI development.

\section{Acknowledgements}

This work was supported by independent scientific research project of Wuhan University, Wuhan, Hubei, China (Grant number: 2042017kf0106) and from the National Natural Science Foundation of China (NSFC) (No. 81172793, 81370800, 81500516).

\section{Disclosure Statement}

The authors declare no competing interests.

\section{References}

1 Zuk A, Bonventre JV: Acute Kidney Injury. Annu Rev Med 2016;67:293-307.

1 Chawla LS, Eggers PW, Star RA, Kimmel PL: Acute kidney injury and chronic kidney disease as interconnected syndromes. N Engl J Med 2014;371:58-66. 


\section{Kidney \\ Blood Pressure Research}

- Huen SC, Cantley LG: Macrophages in Renal Injury and Repair. Annu Rev Physiol 2017;79:449-469.

4 Pressly JD, Park F: DNA repair in ischemic acute kidney injury. Am J Physiol Renal Physiol 2017;312:F551-F555.

5 Bonventre JV, Yang L: Cellular pathophysiology of ischemic acute kidney injury. J Clin Invest 2011;121:4210-4221.

6 Wei Q Xiao X, Fogle P, Dong Z: Changes in metabolic profiles during acute kidney injury and recovery following ischemia/reperfusion. PLoS One 2014;9:e106647.

$>7$ Yu TM, Palanisamy K, Sun KT, Day YJ, Shu KH, Wang IK, Shyu WC, Chen P, Chen YL, Li CY: RANTES mediates kidney ischemia reperfusion injury through a possible role of HIF-1alpha and LncRNA PRINS. Sci Rep 2016;6:18424.

-8 Danobeitia JS, Ziemelis M, Ma X, Zitur LJ, Zens T, Chlebeck PJ, Van Amersfoort ES, Fernandez LA: Complement inhibition attenuates acute kidney injury after ischemia-reperfusion and limits progression to renal fibrosis in mice. PLoS One 2017;12:e0183701.

- Liu Z, Wang S, Mi QS, Dong Z: MicroRNAs in Pathogenesis of Acute Kidney Injury. Nephron 2016;134:149153.

10 Godwin JG, Ge X, Stephan K, Jurisch A, Tullius SG, Iacomini J: Identification of a microRNA signature of renal ischemia reperfusion injury. Proc Natl Acad Sci U S A 2010;107:14339-14344.

11 Lorenzen JM, Kaucsar T, Schauerte C, Schmitt R, Rong S, Hubner A, Scherf K, Fiedler J, Martino F, Kumarswamy R, Kolling M, Sorensen I, Hinz H, Heineke J, van Rooij E, Haller H, Thum T: MicroRNA-24 antagonism prevents renal ischemia reperfusion injury. J Am Soc Nephrol 2014;25:2717-2729.

12 Krishnamoorthy A, Ajay AK, Hoffmann D, Kim TM, Ramirez V, Campanholle G, Bobadilla NA, Waikar SS, Vaidya VS: Fibrinogen beta-derived Bbeta(15-42) peptide protects against kidney ischemia/reperfusion injury. Blood 2011;118:1934-1942.

13 Bolstad BM, Irizarry RA, Astrand M, Speed TP: A comparison of normalization methods for high density oligonucleotide array data based on variance and bias. Bioinformatics 2003;19:185-193.

14 Diboun I, Wernisch L, Orengo CA, Koltzenburg M: Microarray analysis after RNA amplification can detect pronounced differences in gene expression using limma. BMC Genomics 2006; 7:252.

15 Picaud S, Wells C, Felletar I, Brotherton D, Martin S, Savitsky P, Diez-Dacal B, Philpott M, Bountra C, Lingard H, Fedorov O, Muller S, Brennan PE, Knapp S, Filippakopoulos P: RVX-208, an inhibitor of BET transcriptional regulators with selectivity for the second bromodomain. Proc Natl Acad Sci U S A 2013;110:19754-19759.

-16 Huang DW, Sherman BT, Tan Q Collins JR, Alvord WG, Roayaei J, Stephens R, Baseler MW, Lane HC, Lempicki RA: The DAVID Gene Functional Classification Tool: a novel biological module-centric algorithm to functionally analyze large gene lists. Genome Biol 2007;8:R183.

17 von Mering C, Huynen M, Jaeggi D, Schmidt S, Bork P, Snel B: STRING: a database of predicted functional associations between proteins. Nucleic Acids Res 2003;31:258-261.

18 Shannon P, Markiel A, Ozier O, Baliga NS, Wang JT, Ramage D, Amin N, Schwikowski B, Ideker T: Cytoscape: a software environment for integrated models of biomolecular interaction networks. Genome Res 2003;13:2498-2504.

19 Zhang B, Kirov S, Snoddy J: WebGestalt: an integrated system for exploring gene sets in various biological contexts. Nucleic Acids Res 2005;33:W741-748.

20 Gomez IG, Nakagawa N, Duffield JS: MicroRNAs as novel therapeutic targets to treat kidney injury and fibrosis. Am J Physiol Renal Physiol 2016;310:F931-944.

-21 Inoue T, Tanaka S, Okusa MD: Neuroimmune Interactions in Inflammation and Acute Kidney Injury. Front Immunol 2017;8:945.

22 Subraman V, Thiyagarajan M, Malathi N, Rajan ST: OPN -Revisited. J Clin Diagn Res 2015;9:ZE10-13.

23 Noiri E, Dickman K, Miller F, Romanov G, Romanov VI, Shaw R, Chambers AF, Rittling SR, Denhardt DT, Goligorsky MS: Reduced tolerance to acute renal ischemia in mice with a targeted disruption of the osteopontin gene. Kidney Int 1999;56:74-82.

24 Zhang ZX, Shek K, Wang S, Huang X, Lau A, Yin Z, Sun H, Liu W, Garcia B, Rittling S, Jevnikar AM: Osteopontin expressed in tubular epithelial cells regulates NK cell-mediated kidney ischemia reperfusion injury. J Immunol 2010;185:967-973. 


\section{Kidney \\ Blood Pressure Research}

25 Cen C, Aziz M, Yang WL, Nicastro JM, Coppa GF, Wang P: Osteopontin Blockade Attenuates Renal Injury After Ischemia Reperfusion by Inhibiting NK Cell Infiltration. Shock 2017;47:52-60.

-26 Irita J, Okura T, Jotoku M, Nagao T, Enomoto D, Kurata M, Desilva VR, Miyoshi K, Matsui Y, Uede T, Denhardt DT, Rittiling SR, Higaki J: Osteopontin deficiency protects against aldosterone-induced inflammation, oxidative stress, and interstitial fibrosis in the kidney. Am J Physiol Renal Physiol 2011;301:F833-844.

27 Pei Z, Okura T, Nagao T, Enomoto D, Kukida M, Tanino A, Miyoshi K, Kurata M, Higaki J: Osteopontin deficiency reduces kidney damage from hypercholesterolemia in Apolipoprotein E-deficient mice. Sci Rep 2016;6:28882.

-28 Murphy G: Tissue inhibitors of metalloproteinases. Genome Biol 2011;12:233.

-29 Peng L, Yanjiao M, Ai-guo W, Pengtao G, Jianhua L, Ju Y, Hongsheng O, Xichen Z: A fine balance between CCNL1 and TIMP1 contributes to the development of breast cancer cells. Biochem Biophys Res Commun 2011;409:344-349.

-30 Kim H, Oda T, Lopez-Guisa J, Wing D, Edwards DR, Soloway PD, Eddy AA: TIMP-1 deficiency does not attenuate interstitial fibrosis in obstructive nephropathy. J Am Soc Nephrol 2001;12:736-748.

31 Cai G, Zhang X, Hong Q, Shao F, Shang X, Fu B, Feng Z, Lin H, Wang J, Shi S, Yin Z, Chen X: Tissue inhibitor of metalloproteinase-1 exacerbated renal interstitial fibrosis through enhancing inflammation. Nephrol Dial Transplant 2008;23:1861-1875.

32 Won AJ, Kim S, Kim YG, Kim KB, Choi WS, Kacew S, Kim KS, Jung JH, Lee BM, Kim S, Kim HS: Discovery of urinary metabolomic biomarkers for early detection of acute kidney injury. Mol Biosyst 2016;12:133-144.

33 Bojic S, Kotur-Stevuljevic J, Kalezic N, Stevanovic P, Jelic-Ivanovic Z, Bilanovic D, Memon L, Damnjanovic M, Kalaba Z, Simic-Ogrizovic S: Diagnostic Value of Matrix Metalloproteinase-9 and Tissue Inhibitor of Matrix Metalloproteinase-1 in Sepsis-Associated Acute Kidney Injury. Tohoku J Exp Med 2015;237:103-109.

-34 Binzak BA, Wevers RA, Moolenaar SH, Lee YM, Hwu WL, Poggi-Bach J, Engelke UF, Hoard HM, Vockley JG, Vockley J: Cloning of dimethylglycine dehydrogenase and a new human inborn error of metabolism, dimethylglycine dehydrogenase deficiency. Am J Hum Genet 2001;68:839-847.

-35 Van den Eynden J, Ali SS, Horwood N, Carmans S, Brone B, Hellings N, Steels P, Harvey RJ, Rigo JM: Glycine and glycine receptor signalling in non-neuronal cells. Front Mol Neurosci 2009;2:9.

-36 Yin M, Zhong Z, Connor HD, Bunzendahl H, Finn WF, Rusyn I, Li X, Raleigh JA, Mason RP, Thurman RG: Protective effect of glycine on renal injury induced by ischemia-reperfusion in vivo. Am J Physiol Renal Physiol 2002;282:F417-423.

-37 Arora S, Kaur T, Kaur A, Singh AP: Glycine aggravates ischemia reperfusion-induced acute kidney injury through N-Methyl-D-Aspartate receptor activation in rats. Mol Cell Biochem 2014;393:123-131.

-38 Gholaminejad A, Abdul Tehrani H, Gholami Fesharaki M: Identification of candidate microRNA biomarkers in renal fibrosis: a meta-analysis of profiling studies. Biomarkers 2018;16:1-12.

39 Zhu HY, Liu MY, Hong Q Zhang D, Geng WJ, Xie YS, Chen XM: Role of microRNA-181a in the apoptosis of tubular epithelial cell induced by cisplatin. Chin Med J (Engl) 2012;125:523-526.

40 Wang Z, Famulski K, Lee J, Das SK, Wang X, Halloran P, Oudit GY, Kassiri Z: TIMP2 and TIMP3 have divergent roles in early renal tubulointerstitial injury. Kidney Int 2014;85:82-93.

41 Schrimpf C, Xin C, Campanholle G, Gill SE, Stallcup W, Lin SL, Davis GE, Gharib SA, Humphreys BD, Duffield JS: Pericyte TIMP3 and ADAMTS1 modulate vascular stability after kidney injury. J Am Soc Nephrol 2012;23:868-883.

42 Basile DP, Fredrich K, Chelladurai B, Leonard EC, Parrish AR: Renal ischemia reperfusion inhibits VEGF expression and induces ADAMTS-1, a novel VEGF inhibitor. Am J Physiol Renal Physiol 2008;294:F928-936.

-43 Feng W, Tang R, Ye X, Xue C, Liao Y: Identification of Genes and Pathways Associated with Kidney IschemiaReperfusion Injury by Bioinformatics Analyses. Kidney Blood Press Res 2016;41:48-54. 